\title{
The invisible risks: Spotting the hazards in your orthodontic practice: A review
}

\author{
Dr. Sheron Bhanat ${ }^{1}$, Dr. Roopal Patel ${ }^{2}$, Dr. Dolly Patel ${ }^{3}$ \\ ${ }^{I}$ Senior Lecturer; Department of Orthodontics; AMC Dental College and Hospital, Ahmedabad, Gujarat, India. \\ ${ }^{2}$ Reader; Department of Orthodontics; AMC Dental College and Hospital, Ahmedabad, Gujarat, India. \\ ${ }^{3}$ The Dean and Head of the Department; Department of Orthodontics; AMC Dental College and Hospital, \\ Ahmedabad, Gujarat, India.
}

\begin{abstract}
Professional risk factors in orthodontics may harm orthodontists and their team. Despite numerous technical advances in recent years, many occupational health problems still persist in modern dentistry. These includes exposure to infectious diseases, radiation, dental materials, and noise; musculoskeletal disorders; dermatitis and respiratory disorders; eye injuries; and psychological problems. It is essential for an orthodontist to recognize these risk factors and protect against them.

The scientific and clinical literatures on occupational hazards in orthodontics is reviewed to identify and recognize the risks, new guidelines, precautions and protocols are rapidly instituted to greatly reduce or even eliminate the occupational hazard.
\end{abstract}

Keywords: Risk factors; Occupational hazards; Orthodontic practice; Ergonomics; Psychological factor

\section{Introduction}

Dental professionals and their patients are constantly exposed to a number of specific occupational hazards. Being unaware of the potential hazards in the work environment makes them more vulnerable to injury. In many cases, these exposures result in diseases, which are regarded as occupational illnesses. These range from toxicity from chemicals routinely used in dentistry and threat of cross-infection in the dental clinic to musculoskeletal diseases consequential to sub-optimal working posture. Such hazards cause the appearance of various ailments that are specific to the profession and that develop and intensify over the years. Awareness of these occupational hazards and implementation of preventive strategies can provide a safe dental environment for all concerned. The purpose of this article was to review and assess the health risk of practicing orthodontists and to increase the level of awareness of occupational hazards amongst them. In orthodontics, occupational hazards can be broadly categorized by source of hazards as: ${ }^{1,2}$

1. Health hazards impose threats to a person's biological balance from exposure to:

a. Physical factors: lights, noise, vibration, heat, trauma etc.

b. Chemical factors: latex, monomer, sterilization, aerosols, radiology liquids etc.

c. Biological factor: infections

2. Other hazards include risks to the professional's well-being, associated with:

a. Musculoskeletal problems: muscular pain, stiffness of muscles, restricted movements etc.

b. Psychological factors: dealing with patients, work organization, legal action etc.

\section{Health hazards}

Many dental care professionals are at risk for occupational exposure to a variety of hazards like physical, chemical and biological conditions. The following references aid in recognizing, controlling and preventing hazards in the workplace.

a. Physical factors:

In orthodontic practice, orthodontists get exposed to various physical factors such as light, noise, heat trauma etc.

Light affects the eyes and vision. Workplace lighting and dental chair light are the most common form of light which is used during daily procedures. Recently, lasers and orthodontic curing light were introduced in orthodontics; hazards apply to the different sources depending on the wavelength range of the emitted radiation and exposure time of each application. The hazards associated with these lights are eye strain, dry eye syndrome, cataract, maculopathies etc ${ }^{3,4}$. The other risk of eye hazards from penetrating injuries such as wire segments or adhesive chips from debonding, chemical burn from acids or alkalis like bonding etching material, disinfectants or other liquids and sprays. Common symptoms of eye syndrome include irritation, foreign body sensations, burning sensation, and itching, blurred vision. The majority of dental procedures are accomplished 
with instruments being passed over or near the patient's face and with aerosols and chemicals frequently in close proximity; both patients and dentists should wear eye protection. Sims and Roberts-Harry ${ }^{5}$ reported that $43 \%$ of orthodontists reported instances of ocular injury in their practices. The majority of these injuries occurred during debonding or trimming acrylic.

Noise is always present during the dental work; it is divided into distracting noise like crowd chatter, loud office music, air conditioners etc. and destructive noise like high-speed turbine handpieces, low-speed handpieces, high-velocity suction, ultrasonic instruments and cleaners, vibrators and other mixing devices, and model trimmers. This division results from the variety of parameters determining sound hazards and their influence. The degree of risk might depend on several factors including age, personal susceptibility, and total daily exposure. The effects of dental sounds inducing hearing loss can be diminished by usage of insulation whenever possible, using ear plugs during laboratory procedures ${ }^{6,7}$.

Occupational injuries of health professionals are another area of interest. In orthodontics, sharp injuries occur because of a small operating field, frequent patient movement, and the variety of sharp instruments (e.g. Cutter) or material (e.g. orthodontic wire, pins) used in orthodontic procedure ${ }^{8}$. In 1998, a survey of percutaneous injuries in orthodontics conducted by Bagramian and McNamara ${ }^{8,9}$ sponsored by American Association of Orthodontists found that orthodontists showed a low yearly injury rate of less than $1 \%$, with $84 \%$ injuries occurred outside the mouth; this is important finding, since doctor - patient contact during injury is minimal. Most common injuries occurred during wire changes. S L Farrier ${ }^{10}$ reported risks encountered within the dental environment cause harm to the unprotected eyes of both staff and patients. $48 \%$ of general dental practitioners had experience of ocular trauma or infection which occurred during a variety of procedures; $75 \%$ of these injuries resulted from not wearing eye protection. Most of the injuries can be treated on site without long term effect. Extra caution should be used during laboratory procedures, when injuries from projectiles are possible ${ }^{11,12}$.

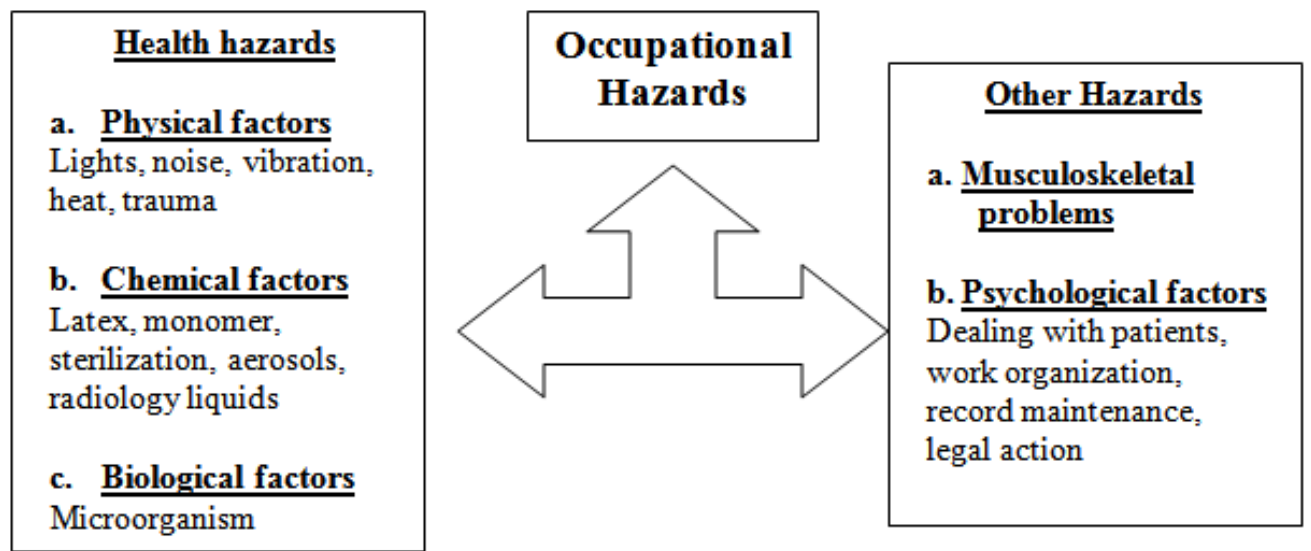

Figure 1: Source of occupational hazards in orthodontic work area

b. Chemical factors:

In clinical orthodontic practice and in the laboratory, a number of chemicals are used which include latex, polymer materials, acrylic resins, cements, etching material, waxes, and impression materials, sterilization and radiology fluid.

Although gloves enhance the barrier abilities of the skin and help decrease cross contamination, adverse reaction to latex are side effects ${ }^{11}$. Healthcare persons exposed to latex-containing products on a regular basis show higher sensitivity. The etiology of latex sensitivity is based on a reaction to the plant containing allergenic proteins in natural rubber. Referred to as Type I allergy to natural rubber latex protein, allergic reactions can be severe and sometimes fatal. The American Dental Association (ADA) began investigating the prevalence of Type I latex hypersensitivity in dental personnel in 1994. At that time, over 2000 dentists, hygienists, and assistants volunteered for testing at the 1994 and 1995 ADA Annual Sessions. Results showed that $6.2 \%$ of participants tested were positive for Type I latex hypersensitivity. Data from 1996 to 2001 from this ongoing cross-sectional study showed a decline in prevalence from $8.5 \%$ to $4.3 \%$. Synthetic gloves (vinyl, nitrile) were introduced as alternative for latex sensitive persons ${ }^{14,15}$.

Latex gloves dusted with cornstarch powder are more often used in dental practice. Corn starch is allergenic and gives immediate allergic reactions. Starch particles combined with latex protein allergens become airborne, and is inhaled, or absorbed by our skin. In vitro evaluation of natural latex, synthetic rubber, and synthetic polymeric glove materials showed various degrees of cytotoxicity; this introduced silicone, powderfree gloves which have less risk. The clinical symptoms of latex allergies include: of eyelids, mucous rhinitis, 
bronchial asthma and anaphylactic anaphylactic shock. Corn-starch or the so called absorbable dusting powder also plays an important role in latex allergies, manifesting itself in the reaction on the part of airways ${ }^{15}$.

Irreversible hydrocolloid powder contains about $60 \%$ diatomaceous earth. When fluffed, these particles in the size of less than $3 \mu \mathrm{m}$ in diameter and greater than $20 \mu \mathrm{m}$ in length can be inhaled and may prove to be a health risk (carcinogenic) over a long time span. Improper handling of daily use materials like irreversible hydrocolloid materials, alginate, elastomeric impression material etc. in the dental office could be hazardous to the health of dental personnel ${ }^{16}$.

Etching material, monomer, disinfectant and radiology fluids are commonly used in orthodontic practice. Chemical burns come from acids (e.g. bonding etching material) or alkaline (e.g. disinfectant solutions) substances. Acids are usually less harmful than alkalis. Other symptoms occur with chemicals are irritation to skin, mucous membrane, respiratory problem, conjunctival symptoms, headache, irritability etc. There are many potentially toxic materials that are used in dentistry that may pose health hazards in the absence of precautionary measures. Careful handling of chemical materials, according to manufacturer's directions, and sufficient ventilation are recommended ${ }^{17,18}$.

c. Biological factors:

Biological factors include microorganisms and particles. In dental practice, the main source of infections is by getting infected through the patient. The main entry points of infection for a dentist include direct contact with blood, body fluid, secretions and excretions, regardless of blood presence, non-intact skin and mucous membranes. Orthodontists are exposed to high level of aerosols by orthodontic procedure, indirect contact with contaminated instruments, surfaces, equipment, materials, inhalation of suspended microorganism or contact of sensitive body area with infected droplets expelled from infected persons at short range ${ }^{19,20}$.

Impression material and orthodontic appliances could be a source of infection. When plaster is poured into a contaminated impression, the microorganisms from its surface spread into the cast, and this infected cast is handled in the dental laboratory. The plaster dust from the infected casts gets into the respiratory tract, settles on clothes and environmental surfaces, and remains viable for a considerable time ${ }^{17}$. For example, Mycobacterium tuberculosis remains dangerous for several weeks. Impression material can act as a vehicle for the transfer of both pathogenic bacteria and viruses and cause cross contamination in the clinic and from the clinic to the laboratory. Infection control procedures such as attention to general hygiene, appropriate sharp disposal, personal protective measures, sterilization or high level disinfection remains the best defense, not only to the dentist but also to help transmission of infectious agents between dental patients ${ }^{21,22,23}$.

\section{Other hazards}

a. Musculoskeletal problems:

Occupation related diseases are increasing nowadays and one amongst them is musculoskeletal disorder which occurs due to improper ergonomics in dentistry. Many of the researchers believe that awkward body posture and low movement are the sources of occupational disorders. Therefore, knowledge of ergonomic risk factors in dental office design is very important. Dentist have to bend their bodies while using a variety of elaborate hand tools in order to perform work in oral cavity. They are required to maintain these positions for a prolonged period of time. This creates a problem of having static contractions and subsequently developing muscle ischemia. Muscle ischemia is thought to be a primary cause of myofacial trigger points, which can result in pain, restriction movements and muscular atrophy. Dental professionals are notably affected with musculoskeletal diseases in their career. According to a Anna Keirklo ${ }^{24}$ et al, 92\% of dentists reported musculoskeletal compliant, especially in the neck $47 \%$ and lower back 35\%; $29 \%$ showed trouble in finger, $23 \%$ with hip, whereas $20 \%$ demonstrated problem in mid back.

Orthodontists are at high risk of neck and back problems due to the limited work-area and impaired vision associated with the oral cavity. These working restrictions frequently cause them to assume stressful body positions to achieve good access and visibility inside the oral cavity which result in awkward positions over long periods of time; which in turn result in back problems. The symptoms include low back pain, stiffness, and sciatica with neurological features such as tingling, paresthesia, and muscle weakness. Tendinopathies and Carpal tunnel syndrome were associated with both repetitive work and forceful work ${ }^{24}$. 25 . The risk of musculoskeletal disorders (MSD) can be prevented by maintaining an erect posture (minimize forward bending), relaxed natural body position, changing posture as frequently as possible, using ergonomically designed equipment and tools, taking regular breaks between treatment procedures ${ }^{26}$

\section{b. Psychological factors:}

Occupational stress such as dealing with difficult or uncooperative patients, work overload, record keeping, and a constant drive for technical perfection, legal action and dissatisfaction in treatment is common among orthodontists $^{27,28}$. Other sources of psychological factors are related to finance, job-growth, dentist-patient relations, staff and technical problems, time management. Apart from these other psychological problems are professional burnouts, anxiety disorder, and depression. Professional burnout is common among dentists due to emotional exhaustion, psychological 
fatigue and reduced personal accomplishment. In some cases, it can also lead to Generalized Anxiety Disorder which is characterized by chronic exaggerated worry and tension due to non-trivial reasons. A comparison of stress levels and coping stress in male and female dentists showed that stress levels were similar, although female dentists experienced more personal and domestic stress.

High levels of occupational stress among dentists are correlated with hypertension, neurological and mental problems, cardiac problems, alcohol consumption ${ }^{28,29}$, and suicide.

Psychological factors can be mitigated by various stress management exercises like progressive relaxation of areas of the body, task management, time management, communication; physical exercises; having a strong positive attitude ${ }^{30}$. A Study by Lowe $\mathbf{L}^{32}$ et al reported that the most common factors contributing to stress at work were patient demands $(75 \%)$, practice management/staff issues (56\%), fear of complaints/litigation (54\%) and non-clinical paperwork (54\%).These physical and emotional demands result in physical and mental burnout.

Cary L. Cooper et $\mathbf{a l}^{33}$ mentioned a study by Russek (In 60s) which concluded that coronary heart disease among dentists is not linked to heredity or diet, but rather to the relative stressfulness of occupational activity. His research focused on four categories of dentistry; periodontia, orthodontia, oral surgery and general practice. They were ranked in order of stressfulness by seven expert independent judges (all dentists), who determined that the most stressful of the fields was general practice followed by oral surgery, orthodontia, and the least stressful, periodontia.

Table 1: Summary of hazards in orthodontic practice and Routine protocol to reduce exposure.

\begin{tabular}{|c|c|c|}
\hline Effects on; & Hazards related to various factors & Routine protocol to reduce exposure \\
\hline \multicolumn{3}{|c|}{ Orthodontic office area and radiology area } \\
\hline Vision & $\begin{array}{l}\text { Eye strain, Eye trauma, Infection, Dry } \\
\text { eye syndrome, irritation, Conjuctival } \\
\text { symptoms, Radiation hazards }\end{array}$ & $\begin{array}{l}\text { Always use protective eyewear for all orthodontic procedures, } \\
\text { Avoid prolong concentration, Avoid splashes during rinsing and } \\
\text { spraying, Follow guidelines for infection control }\end{array}$ \\
\hline Hearing & $\begin{array}{l}\text { Handpiece noise, Ultrasonic scaler, } \\
\text { Office music, Airconditioners, High } \\
\text { velocity suction, X-ram machines }\end{array}$ & $\begin{array}{l}\text { Check noise level of operator sites, use insulation whenever } \\
\text { possible }\end{array}$ \\
\hline Respiratory & $\begin{array}{l}\text { Inhalation of chemicals, allergens, } \\
\text { Aerosol particles, Infection }\end{array}$ & $\begin{array}{l}\text { Maintain proper ventilation, use masks, Follow guidelines for } \\
\text { infection control }\end{array}$ \\
\hline Skin & $\begin{array}{l}\text { Chemical burns, Allergy, Trauma, } \\
\text { Infection }\end{array}$ & $\begin{array}{l}\text { Always use protective barriers like gloves, mask, wear long sleeves } \\
\text {, Lead apron and radiation level sensors to deal with radiation } \\
\text { hazards, Follow guidelines for infection control }\end{array}$ \\
\hline Musculoskeletal & $\begin{array}{l}\text { Neck and back problems, Muscle } \\
\text { ischemia, Tendinopathies, Carple } \\
\text { tunnel syndrome }\end{array}$ & $\begin{array}{l}\text { Relaxed natural body position, Change postures frequently, use } \\
\text { ergonomically designed equipment and tools }\end{array}$ \\
\hline \multicolumn{3}{|c|}{ Laboratory area } \\
\hline Vision & $\begin{array}{l}\text { Eye strain, Eye trauma, Infection, Dry } \\
\text { eye syndrome, irritation, }\end{array}$ & $\begin{array}{l}\text { Always use protective eyewear, Good ventilation reduce aerosols } \\
\text { and vapor hazards, Follow guidelines for infection control }\end{array}$ \\
\hline Hearing & $\begin{array}{l}\text { Vibrator and other mixing devices, } \\
\text { Model trimmer, Different distracting } \\
\text { noise }\end{array}$ & $\begin{array}{l}\text { Check noise level of operator sites, usage of insulation whenever } \\
\text { possible, Ear plugs during laboratory procedures }\end{array}$ \\
\hline Respiratory & $\begin{array}{l}\text { Inhalation of chemicals, allergens, } \\
\text { Aerosol particles, Infection }\end{array}$ & $\begin{array}{l}\text { Good ventilation reduce aerosols and vapor hazards, Follow } \\
\text { guidelines for infection control }\end{array}$ \\
\hline Skin & Allergy, Trauma, Infection, Burning & $\begin{array}{l}\text { Always use protective barriers like gloves, mask, wear long } \\
\text { sleeves, Follow guidelines for infection control }\end{array}$ \\
\hline Musculoskeletal & $\begin{array}{l}\text { Neck and back problems, Muscle } \\
\text { ischemia, Tendinopathies, Carple } \\
\text { tunnel syndrome, Stiffness, Scitica } \\
\text { with neurological features }\end{array}$ & $\begin{array}{l}\text { Use ergonomically designed equipment and tools, laboratory area, } \\
\text { Easy access to frequently used instruments and equipments, Adopt } \\
\text { proper body position }\end{array}$ \\
\hline \multicolumn{3}{|l|}{ Sterilization area } \\
\hline Vision & $\begin{array}{l}\text { Eye strain, Eye trauma, Infection, Dry } \\
\text { eye syndrome, irritation, Conjuctival } \\
\text { symptoms }\end{array}$ & $\begin{array}{l}\text { Always use protective eyewear, Good ventilation reduces aerosols } \\
\text { and vapor hazards, Follow guidelines for infection control }\end{array}$ \\
\hline Hearing & $\begin{array}{l}\text { Noise of different autoclave, } \\
\text { Ultrasonic cleaner }\end{array}$ & Use insulation whenever possible \\
\hline Respiratory & $\begin{array}{l}\text { Inhalation of chemicals, allergens, } \\
\text { Aerosol particles, Infection }\end{array}$ & $\begin{array}{l}\text { Good ventilation reduce aerosols and vapor hazards, Follow } \\
\text { guidelines for infection control }\end{array}$ \\
\hline Skin & $\begin{array}{l}\text { Chemical burns, Allergy to chemicals, } \\
\text { Trauma, Infection }\end{array}$ & Cover all skin areas, Follow guidelines for infection control \\
\hline Musculoskeletal & Neck, shoulder and back problems & Use ergonomically designed equipment and tools etc. \\
\hline
\end{tabular}

\section{Conclusion}

Occupational hazards are invisible risks in orthodontic practice. Highly competitive work-environment and stressful work conditions can adversely affect the health of an orthodontist. Hence, it is very important for an individual to be aware of the risks associated with this profession and to take necessary precautions against it. Concerning prevention of occupational health hazards, the global literature focuses strictly on control of infections and appropriate management of potentially infected materials, owing to the high profile of dentistry regarding infection transmission. Barrier utilities such as gloves, masks, protective eye wear, high power 
suction, and good ventilation reduce aerosols and vapor hazards. Hypoallergenic non-latex gloves can decline latex allergy Lead aprons, periodic maintenance of the X-ray machine and radiation level sensors deal with radiation dangers. The practice of good ergonomics is a significant strategy for the prevention of MSDs (musculoskeletal disorders). Ergonomics in orthodontics is the study of the relationship of humans or clinicians to their working environment and the development of methods, tools, and equipment to improve working conditions, increase efficiency, and reduce injury. In realistic terms, this means selecting and appropriately using equipment that allows for comfortable postures, using instruments that minimize gripping force and vibration, positioning the patient to allow maximum access and visibility with minimal bending and leaning, maintaining good general health, and recognizing and addressing the warning signals for MSDs early in their progress. Continuous educating and appropriate intervention studies are needed to reduce the complication of these hazards. So, it is important for dentists to remain constantly updated about measures on how to deal with newer strategies and dental materials, and implicates the need for special medical care for this professional group $^{1,2,13,31}$

\section{References}

[1] Nikolaos Pandis,Brandi D. Pandis, Vasilios Pandis, Theodore Eliades. Occupational hazards in orthodontics: A review of risks and associated pathology. Am J Orthod Dentofacial Orthop, 132, 2007, 280-292

[2] Prashant S. Viragi, Anil V. Ankola, Mamatha Hebbal. Occupational hazards in dentistry - Knowledge attitudes and practices of dental practitioners in Belgaum city. Journal of Pierre Fauchard Academy 27, 2013, 90-94

[3] Jamshid Ayatollahi, Fatemah Ayatollahi, Ali Mellat Ardekani. Occupational hazards to dental staff. Dent Res J (Isfahan), 9, 2012, 2-7.

[4] I.A. Al-Khatib,M. Ishtayeh, H. Barghouty,and B. Akkawi. Dentists' perceptions of occupational hazards and preventive measures in East Jerusalem. Eastern Mediterranean Health Journal, 12, .2006,153-159.

[5] Strobl K, Bahns TL, Wilham L, Bishara SE. Laser-aided debonding of orthodontic ceramic brackets. Am J Orthod Dentofacial Orthop, 101, $1992,152-158$

[6] A P Sims, T J Roberts-Harry D P Roberts-Harry. The incidence and prevention of ocular injuries in orthodontic practice. Journal of Orthodontics ,20, 1993,339-343

[7] McNamara JA, Bagramian RA. A prospective survey of percutaneous injuries to orthodontic assistant. Am J Orthod Dentofacial Ortho, 115, 1999, 72-76.

[8] S L Farrier, J N Farrier, A S M Gilmour. Eye safety in operative dentistry — A study in general dental practice. British Dental Journal, 200, 2006, 218-223.

[9] Alli AI-L. Rahko, Pekka H. Karma, K. Tapani Rahko, Matti J. Kataja. High-frequency hearing of dental personnel Occupational Hazards. Community Dentistry and Oral Epidemiology,16, 1988, 268-270.

[10] Mojarad F, Massum T, Samavat H. Noise levels in dental offices and laboratories in Hamedan, Iran. J Dent., 6, 2009,181-186.

[11] K. Porter, C. Scully, Y. Theyer, S. Porter. Occupational injuries to dental personnel. , 18, 1990, $258-262$.

[12] Juveria syed ali hussain. Sabita M Ram, Jyotsna Galinde. Occupational exposure to sharp instrument injury among dental, medical and nursing students in Mahatma Gandhi Mission's campus, Navi Mumbai ,India. Journal of contemporary Dentistry, 2, 2012 , 1-10.

[13] W. Willee. How to avoid the occupational hazards of dentistry. Australian Dental Journal, 12, 1967, 348-359

[14] E. Larson, E.K. Kretzer. Compliance with handwashing and barrier precautions. Journal of Hospital Infection, 30, $1995,88-106$.

[15] E.A. Field. The use of powdered gloves in dental practice: a cause for concern? Journal of Dentistry, 25, 1997, $209-214$.

[16] Anders Tillberg, Bengt Järvholm, Anders Berglund. Risks with dental materials. Dental Materials, 24, 2008, 940-943.

[17] N Torbica, S Krstev. World at work (prosthodontics) Occup Environ Med, 63,2006, 145-148

[18] Hensten-Pettersen A, Jacobsen N .The role of biomaterials as occupational hazards in dentistry. International Dental Journal,40, 1990, 159166

[19] A M Bennett, M R Fulford, J T Walker, D J Bradshaw, M V Martin, P D Marsh. Microbial aerosols in general dental practice. British Dental Journal, 189, 2000, $664-667$.

[20] Toroglu MS, Byramoglu, A possiblility of blood and hepatitis contamination through aerosols generated during debonding procedure. Angle orthod , 189, 2003, 664-6

[21] Peter M. Greco, Chern-Hsiung Lai. A new method of assessing aerosolized bacteria generated during orthodontic debonding procedures. Am J Orthod Dentofacial Orthop, 133, 2008, 9-87.

[22] A Behroozy. On dermal exposure assessment. Int J Occup Environ Med, 4, 2013, 113-127.

[23] Watt RG, Croucher R. Dentists' perceptions of HIV/AIDS as an occupational hazard: a qualitative investigation. International Dental Journal, 41, 1991, 259-264.

[24] Anna keirklo, Agniszka kobus. Work-related musculoskeletal disorders among dentist-A questionnaire survey. Ann Agric Envion Med, 18, 2011, 79-84.

[25] Hayes MJ, Cockrell D, Smith DR. A systematic review of musculoskeletal disorders among dental professionals. Int J Dent Hyg,7, 2009, $159-65$

[26] Avesh Sachan, Vinay Kumar Verma, Sujit Panda, Karuna Singh. Ergonomics, posture and exercises - Painfree, prolong orthodontic career. $J$ Orthod Res ,1, 2013, 89-94

[27] E. D. Marshall, R. Q. Robinson, S. L. Kilbreath. Musculoskeletal symptoms in New South Wales dentists. Australian Dental Journal, 42,1997, 240-246.

[28] Gorter RC, Eijkman MAJ, Hoogstraten J.A career counseling program for dentists: Effects on burnout. Patient Educ Couns,43, 2001, 23-30

[29] Newton JT, Mistry K, Patel A, Patel P, Perkins M, Saeed K. Stress in dental specialists: A comparison of six clinical dental specialties. Prim Dent Care,9, 2002, 100-5.

[30] Roger EA. Stress-related suicide by dentists and other health care workers. J Am Dent Assoc,132, 2001,786-794

[31] Alina Puriene, Jolanta Aleksejuniene, Jadvyga Petrauskiene, Irena Balciuniene, Vilija Janulyte. Occupational hazards of dental profession to psychological Wellbeeing. Stomatologija, Baltic Dental and Maxillofacial Journal,9, 2007, 72-78.

[32] Lowe JC Kay EJ,. A survey of stress levels, self-perceived health and health-related behaviours of UK dental practitioners in 2005. Br Dent J, 2008; 204:E19.

[33] Cary L. Cooper, Mark Mallinger, Richard L. Dentistry: what causes it to be a stressful occupation? Applied Psychology, 29,1980, $307-319$. 